\title{
VI Coloquio de la Asociación Mexicana de Estudios Clásicos (AMEC) Facultad de Filosofía y Letras, UNAM (17 a 19 de febrero de 2016)
}

Los días 17, 18 y 19 de febrero de 2016 en las instalaciones de la Facultad de Filosofía y Letras de la UNAM se celebró el VI Coloquio de la AMEC (Asociación Mexicana de Estudios Clásicos), bajo el título "Diálogo entre Grecia y Roma y su proyección en el mundo contemporáneo". Realizado una vez al año, este evento representa una ocasión propicia para abrir un espacio de encuentro y diálogo entre las personas que, en diversas instancias de México, se dedican al estudio y a la enseñanza de las lenguas clásicas y su recepción, tanto en el nivel bachillerato como en el universitario, dentro y fuera de la UNAM.

Las propuestas recibidas se dividieron en nueve mesas temáticas, fueron integradas cuatro mesas plenarias y se invitó a cinco conferencistas magistrales. Durante el coloquio diversas fueron las cuestiones abordadas, tomando en cuenta las múltiples perspectivas que caracterizan al mundo clásico, así como los acercamientos propios para su estudio y su enseñanza. $\mathrm{El}$ acto inaugural se dio por parte del Consejo Directivo de la Asociación, representado por la doctora Aurelia Vargas Valencia (Presidenta) y la Mtra. Lourdes Santiago Martínez (Vicepresidenta), acompañadas por las Coordinadoras del Centro de Estudios Clásicos del Instituto de Investigaciones Filológicas de la UnAM y del Colegio de Letras Clásicas de la Facultad de Filosofía y Letras de la UNAM, la doctora Martha Elena Montemayor Aceves y la Mtra. Patricia Villaseñor Cuspinera, respectivamente, así como por la doctora Frida Zacaula Sampieri, invitada especial por el bachillerato de la UNAM, y por el señor embajador de la República Helénica en México, Petros Panayotópoulos.

Los trabajos del coloquio se abrieron con la conferencia inaugural del Dr. David García Pérez con el título "Alfonso Reyes y sus aportaciones a los estudios clásicos", que puso el acento en el legado que este importante autor hizo a la tradición clásica de México, analizando también la recepción 
de los modelos clásicos y su vinculación con el contexto a él contemporáneo.

Luego se dio paso a la primera mesa plenaria, que tuvo como argumento la "Enseñanza de las lenguas clásicas en la Licenciatura" por parte del Mtro. David Becerra Islas, profesor de griego, y de la Mtra. Lourdes Santiago Martínez, profesora de latín, quienes expusieron las problemáticas relacionadas con su labor docente respecto del aprendizaje de sus alumnos. Al término de la plenaria empezaron las mesas temáticas, que abordaron por un lado la "Vigencia de los modelos clásicos", por el otro las "Colindancias culturales" entre el mundo clásico y otras realidades y, finalmente, las "Recreaciones de los cánones clásicos en la enseñanza de la lengua". En la tarde se celebró la segunda mesa plenaria titulada "Vidas y recintos femeninos", donde la Dra. Mariateresa Galaz Juárez profundizó en el papel que juegan las mujeres en la obra de Plutarco, mientras la Dra. Martha Cecilia Jaime González analizó el espacio físico en el que se desarrolló la larga espera de la reina Penélope en la ciudad de Ítaca.

El primer día se cerró con la conferencia magistral de la Dra. Elsa Cross titulada "Katábasis de la diosa", con la presentación, acompañada por imágenes, de la transformación del mito de la divinidad que desciende al inframundo y luego regresa, subrayando los elementos comunes a esta recreación mítica a lo largo del tiempo.

El jueves 18, en la mañana, se llevaron a cabo las mesas de "Ciencias de la memoria", "Filosofía y humanismo", "Fuentes clásicas de gramática y retórica" y "Perspectivas de la figura del héroe". La conferencia magistral estuvo a cargo de la Mtra. Natalia Moreleón Guízar quien presentó el "Erotócrito o el juicio del amor: la novela renacentista de Vicenzo Cornaro", obra del siglo XVII que enaltece los valores del helenismo con el estilo propio del modelo veneciano de la época en la que fue escrita.

La tercera mesa plenaria tuvo como argumento la "Enseñanza de las lenguas clásicas en el Bachillerato", con la intervención de la Mtra. Rosenda Romero Martínez y de la Mtra. Aída Ostria Baltazar, de la Escuela Nacional Preparatoria de la UNAM, junto con la Lic. Alejandra Arana Rodríguez del $\mathrm{CCH}$. La discusión se centró en los problemas de tiempo y oportunidades para enseñar de la manera más idónea estas asignaturas y se propusieron algunas posibles soluciones.

Por la tarde continuaron los trabajos del coloquio con la cuarta mesa plenaria acerca de la "Evolución linguiística", con la intervención de la Dra. María Laura Espinoza Gutiérrez titulada "La conjunción subordinante ke del protorromance hispano" y la del Dr. José Paz Espinosa Xolalpa acerca de la "Etimología popular". 
El segundo día se cerró con la conferencia magistral a cargo del Dr. Bernardo Berruecos Frank, "El poema de Simónides (Fr. 531 P) sobre los caídos en las Termópilas", en la que se presentaron los elementos más problemáticos acerca de la interpretación de esta obra y se evidenció cómo la recepción realizada por el autor latino Horacio ofrece una clave de lectura sumamente significativa para acercarse a una posible comprensión del autor griego.

En el último día del coloquio se celebraron las mesas de "Teatro clásico y su tradición" y la de "Ecos literarios", se concluyeron los trabajos con la conferencia de clausura dictada por la Dra. Martha Lilia Tenorio Trillo, la "Vigencia de los clásicos en la tradición hispánica", en la cual se subrayó el influjo de la antigüedad clásica y sus consecuencias en el contexto hispánico, haciendo hincapié en que estamos frente a un diálogo ininterrumpido a lo largo del tiempo entre el mundo clásico y la literatura hispánica, con formas que difieren por contextos, pero no en la sustancia.

Al término de la conferencia, la Presidenta y la Vicepresidenta de la Asociación clausuraron el coloquio haciendo un breve balance y anunciaron la intervención musical a cargo de los alumnos de la Escuela Superior de Música del Instituto Nacional de Bellas Artes, quienes, coordinados por los profesores Pedro Rodríguez y Panayota Zagoura, ofrecieron a todo el público presente una sentida intervención musical, que sirvió de broche de oro a este evento.

El coloquio cumplió con la temática prevista y permitió que los asistentes, durante los tres días, pudieran sumergirse en las múltiples facetas del mundo clásico y reflexionar acerca de los ecos de esta tradición en nuestro presente, así como en los retos urgentes e importantes en el camino de cada uno de los protagonistas (los alumnos, los profesores y, en general, los estudiosos del mundo clásico). En él se probó una nueva estructura para organizar estos encuentros, combinando las modalidades de convocatoria abierta con las de invitación a conferencias magistrales y participación en mesas plenarias, también por invitación; así mismo y de manera relevante, este coloquio se caracterizó por una importante participación de una nueva generación de investigadores y profesores, y por el impulso a líneas emergentes de investigación sobre los estudios clásicos como la arqueología y la epigrafía, reuniendo a los académicos que han comenzado a cultivarlas dentro y fuera de la UNAM.

El coloquio fue, además, el foro ideal para presentar la nueva pagina web de la AMEC (www.asociamec.mx), creada con el propósito de dar visibilidad a la Asociación y sus múltiples actividades, proponiendo la incorporación de nuevos socios y presentando las informaciones pertinentes acerca de 
oportunidades de trabajo para los especialistas en el mundo clásico; en resumidas cuentas, ha sido un espacio único para entender, una vez más y de manera más contundente, la trascendencia de seguir estudiando las letras clásicas en México y la proyección que esta labor tiene en el futuro, próximo y lejano.

Giuditta CAVALLETTI DOI: 10.19130/iifl.nt.2016.33.2.716 